\title{
ST yükselmeli akut miyokard infarktüsü tedavisi
}

\section{The treatment of ST elevation myocardial infarction}

\author{
Serkan Yüksel*, Mahmut Şahin \\ Ondokuz Mayıs Üniversitesi, Tıp Fakültesi, Kardiyoloji Anabilim Dall, Samsun, Türkiye
}

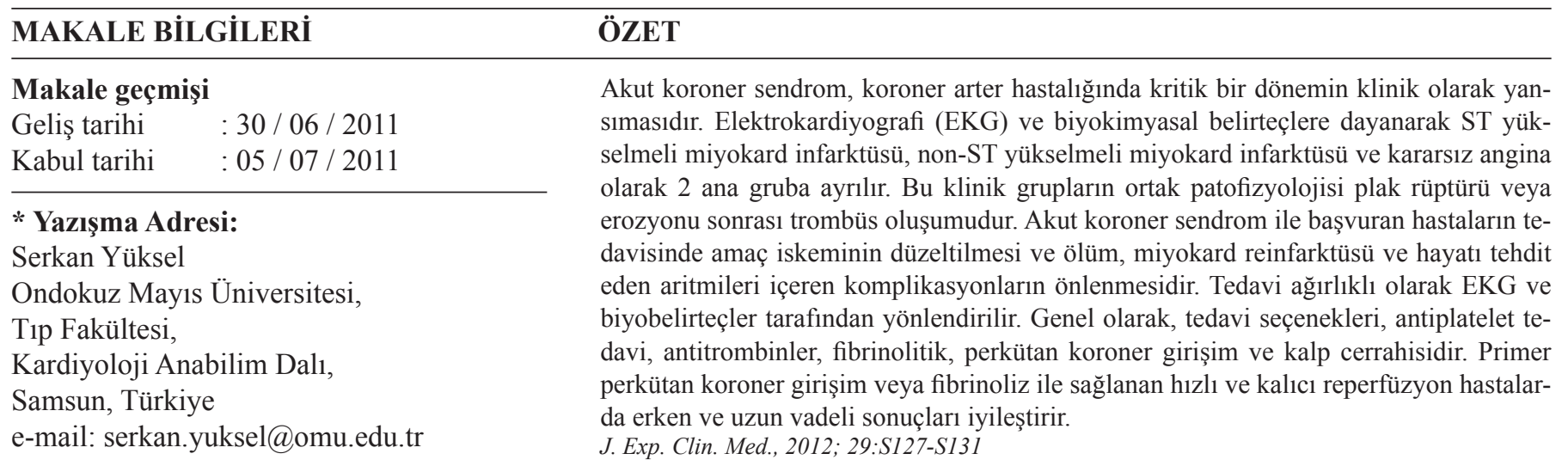

\section{Anahtar Kelimeler:}

Akut koroner sendrom

Fibrinolitik

Koroner arter bypass greft cerrahisi

Perkütan koroner girişim

Reperfüzyon

Revaskülarizasyon

ST yükselmeli miyokard infarktüsü

\section{Keywords:}

Acute coronary syndrome

Fibrinolytics

Coronary artery bypass graft surgery

Percutaneous coronary intervention

Reperfusion

Revascularization

ST elevation myocardial infarction

\begin{abstract}
Acute coronary syndrome is the clinical manifestation of the critical phase of coronary artery disease. Based on electrocardiogram (ECG) and biochemical markers it is distinguished from ST-elevation myocardial infarction, non-ST-elevation myocardial infarction, and unstable angina. The common underlying pathophysiology is related to plaque rupture or erosion with subsequent thrombus formation. Treatment of patients presenting with an acute coronary syndrome aims at immediate relief of ischaemia and the prevention of serious adverse events, including death, myocardial reinfarction, and lifethreatening arrhythmias. The general management is predominately guided by the ECG and biomarkers. In general, treatment options include antiplatelet therapy, antithrombins, fibrinolytics, percutaneous coronary interventions, and cardiac surgery. In patients with ST-segment elevation rapid and sustained reperfusion of the infarct related artery by primary percutaneous coronary intervention or fibrinolysis improves early and long-term outcome.
\end{abstract}

J. Exp. Clin. Med., 2012; 29: S127-S131

\section{Giriş}

Son 50 yılda akut ST yükselmeli miyokard infarktüsünün (STEMI) tedavisindeki değişiklikler hayatı tehdit eden bu durumun sonuçlarının iyileşmesini de sağlamıştır. Koroner yoğun bakım üniteleri ve defibrilatörlerin kullanılması, fibrinolitik ve invazif tedavi gibi reperfüzyon stratejileri ve ek tedaviler 1960'larda \%30 olan hastane içi mortaliteyi günümüzde \%2-5'e kadar geriletmiştir (Hamm ve ark., 2009). Kalıcı ST segment yükselmesi ya da yeni olduğu varsay1lan sol dal bloğu olan, semptom başlangıcından itibaren 12 saat içerisinde başvuran STEMI hastalarında mekanik ya da farmakolojik reperfüzyon, eğer bir kontrendikasyon yoksa mutlaka sağlanmalıdır. Klinik ve/veya elektrokardiyografik olarak devam eden iskemi bulguları olan hastalarda 12 saat sonrasında da reperfüzyon örneğin primer perkütan koroner girişim (PKG) ile sağlanmalıdır (Van de Werf ve ark., 2008).

\section{Fibrinolitik tedavi}

Fibrinolitik tedavinin faydaları birçok çalıșma ile kanıtlanmıştır. Fibrinolitik tedavi semptom başlangıcından sonra 6 saat içinde uygulanan her 1000 hastada 30 erken ölümü önler ve en büyük katkı en yüksek riskli hastalarda görülmektedir 
Tablo 1. Fibrinolitik ajanlar ve kullanım sekilleri (2008 ESC Akut STEMI tedavi kılavuzundan uyarlanmıştır).

\begin{tabular}{ll} 
Streptokinaz & $1500000 \mathrm{U} 30-60$ dakikada IV infüzyon \\
& $15 \mathrm{mg}$ IV bolus \\
Alteplaz (t-PA) & $0,75 \mathrm{mg} / \mathrm{kg} 30 \mathrm{dk}$ 'da, $0,50 \mathrm{mg} / \mathrm{kg} 60 \mathrm{dk}$ 'da IV \\
& Toplam doz $100 \mathrm{mg}$ '1 geçmemeli \\
& $30 \mathrm{dk}$ arayla $10 \mathrm{U}+10 \mathrm{U}$ IV bolus \\
Reteplaz (r-PA) & IV tek bolus \\
& $<60 \mathrm{~kg}$ ise $30 \mathrm{mg}$ \\
& $60-70 \mathrm{~kg}$ ise $35 \mathrm{mg}$ \\
Tenekteplaz & $70-80 \mathrm{~kg}$ ise $40 \mathrm{mg}$ \\
(TNK-tPA) & $80-90 \mathrm{~kg}$ ise $45 \mathrm{mg}$ \\
& $\geq 90 \mathrm{~kg}$ ise $50 \mathrm{mg}$ \\
\hline
\end{tabular}

(Hamm ve ark., 2009). Fibrinolitik Ajanlar Tablo 1'de gösterilmektedir.

Streptokinaz ilk fibrinolitik ajandır ve halen birçok ülkede kullanılmaktadır. GISSI-1 ve ISIS-2 çalışmalarında kontrol tedaviye göre 30 günlük mortalitede $\% 23$ azalma sağlamıştır. (Mauri ve ark., 1989, ISIS-2 (Second International Study of Infarct Survival) Collaborative Group, 1988). Bu ajanla fibrinolizin düşük ama ciddi intrakraniyal kanama riski vardır. GUSTO çalışmasında kullanılan fibrin spesifik bir ajan olan t-PA (alteplaz) streptokinaz ile karşılaştırıldığında tedavi edilen 1000 hastada 10 ilave ölümü önlemiş fakat ek olarak 3 inmeye neden olmuştur (Topol ve ark., 1993). t-PA'nın daha uzun yarı ömürlü bolus olarak kullanılabilecek mutantları geliştirilmiştir.

Çift boluslu r-PA'nın (reteplaz) verilme kolaylığı dışında t-PA'ya bir üstünlüğü bulunamamıştır (Topol ve ark., 1997). Tek boluslu ve kiloya göre ayarlanmış TNK-tPA (tenekteplaz) akselere t-PA'ya 30 günlük mortalitede t-PA'ya eşdeğer olup daha düşük oranda serebral olmayan kanama ve daha az kan transfüzyonu ile ilişkili bulunmuştur (Van De Werf ve ark., 1999). Bolus fibrinolitiklerin etkinliği t-PA’ya benzer olması nedeniyle hastane öncesi kullanımı yaygınlaşmaktadır.

\section{Hastane öncesi fibrinolitik tedavi}

Eldeki veriler hastane öncesi fibrinolizin primer perkütan koroner girişim (PKG) ile benzer sonuçlar sağladığını göstermektedir (Steg ve ark., 2003). Fakat erken başvuran hastalarda hastane öncesi fibrinolizin primer PKG'ye göre benzer ya da daha iyi olduğunu gösteren randomize kontrollü bir çalışma yoktur. Yerinde EKG'yi değerlendirebilecek ya da erken hastaneye iletebilecek eğitilmiş medikal ve paramedikal bir ekibin sağlanması halinde hastane öncesi fibrinoliz tedavi seçeneği olmalıdır. Bu durumda fibrinolitik tedavi hasta ile ilk tıbbi temastan sonra 30 dakika içinde başlanmalıdır (Van de Werf ve ark., 2008).

\section{Fibrinolizin riskleri}

Fibrinolitik tedavi, riskin tedaviden sonraki ilk gün içinde en yüksek olduğu inme ile ilişkilidir. Erken dönemde görülen inmeler genellikle serebral kanama nedenli olup geç dönemde trombotik ya da embolik nedenlerle olmaktadır. İleri yaş, düşük vücut ağırlığı, kadın cinsiyet, daha önceki serebrovasküler hastalık öyküsü ve başvuru sırasında yüksek sistolik ve diyastolik hipertansiyon intrakraniyal kanamanın anlam11 göstergeleri olarak saptanmıştır (Gore ve ark., 1995). Son çalışmalarda intrakraniyal kanama \%0,9-1 olarak bulunmuştur. Majör serebral olmayan kanamalar (kan transfüzyonu gerektiren ya da hayatı tehdit eden kanamalar) tedavi edilen hastaların \%4-13'ünde olabilmektedir (Van De Werf ve ark., 1999).

\section{Fibrinolitik tedavi kontrendikasyonları}

Fibrinolitik tedavinin kesin ve göreceli kontrendikasyonları Tablo 2'de verilmiştir (Van de Werf ve ark., 2008).

\begin{tabular}{|c|c|}
\hline \multicolumn{2}{|c|}{$\begin{array}{l}\text { Fibrinolitik tedavinin kesin ve göreceli } \\
\text { kontrendikasyonları ( } 2008 \text { ESC Akut STEMI } \\
\text { tedavi kılavuzundan uyarlanmıştır). }\end{array}$} \\
\hline Kesin Kontrendikasyonlar & Göreceli Kontrendikasyonlar \\
\hline $\begin{array}{l}\text { Herhangi bir zamanda geçirilmiş } \\
\text { hemorajik inme ya da nedeni } \\
\text { bilinmeyen inme }\end{array}$ & $\begin{array}{l}\text { Son } 6 \text { ay içinde geçici iskemik } \\
\text { atak }\end{array}$ \\
\hline Son 6 ayda geçirilmiş iskemik inme & Oral antikoagülan tedavi \\
\hline SSS travma ya da neoplazmı & $\begin{array}{l}\text { Gebelik ya da post-partum } 1 . \\
\text { Hafta içinde }\end{array}$ \\
\hline $\begin{array}{l}\text { Yeni majör travma/cerrahi/kafa } \\
\text { travması (son } 3 \text { hafta içinde) }\end{array}$ & $\begin{array}{l}\text { Dirençli hipertansiyon (sistolik } \\
>180 \mathrm{mmHg} \text {, ve/veya diyastolik } \\
>110 \mathrm{mmHg} \text { ) }\end{array}$ \\
\hline $\begin{array}{l}\text { Son } 1 \text { ay içinde gastrointestinal } \\
\text { kanama }\end{array}$ & İlerlemiş karaciğer hastalığı \\
\hline Bilinen kanama hastalığı & İnfektif endokardit \\
\hline Aort diseksiyonu & Aktif peptik ülser \\
\hline $\begin{array}{l}\text { Kompresyon uygulanamayan } \\
\text { ponksiyonlar (örn. karaciğer } \\
\text { biyopsisi, lumbar ponksiyon) }\end{array}$ & Dirençli uzun süren resusitasyon \\
\hline
\end{tabular}

Fibrinolitik tedavi sonrası anjiyografi

Fibrinoliz başarılı olduysa (60-90. dakikada ST segmentinin \%50'den fazla rezolüsyonu, reperfüzyon aritmilerinin olması, göğüs ağrısının geçmesi) anjiyografi mutlaka planlanmalıdır. Fibrinoliz sonrası erken dönemdeki protrombotik durum ve tekrar tıkanma riskini en aza indirmek amacıyla başarılı fibrinoliz sonrası 3-24. saatler anjiyografi için en uygun zaman aralığıdır (Van de Werf ve ark., 2008).

\section{Ek antikoagülan ve antiplatelet tedavi}

Aspirinin etkinliği ISIS-2 çalışmasında gösterilmiştir (Gore ve ark., 1995). İlk dozda 150-325 mg enterik kaplı olmayan form çiğnenmelidir, daha sonra düşük doz (75-100 mg/gün) oral olarak alınabilir. Oral alım mümkün değilse intravenöz form (250-500 mg) kullanılabilir. Aspirin ve klopidogreli içeren ikili antiplatelet tedavinin faydası CLARITY ve COMMIT çalışmalarında gösterilmiştir (Le May ve ark., 2005; Sabatine ve ark., 2005). Klopidogrel fibrinolitik tedavi uygulanmış hastalarda mutlaka miyokard infarktüsünün akut fazında kullanılmalıdır.

Heparin fibrinoliz sırasında ve sonrasında yaygın olarak kullanılmaktadır. Heparinin erken dönem liziste etkili olduğu gösterilmese de alteplaz ile beraber koroner açıklığın alteplaz sonrası saatler ve günler sonra devamında etkili olduğu görülmüştür. Fibrinolitik tedavi sonrası 24-48 saat sonra heparin infüzyonu durdurulabilir. Heparin tedavisinin aPTT ile monitorizasyonu çok önemlidir, 70 saniyenin üzerindeki değerlerin yüksek mortalite, kanama ve reinfarktüs ile ilişkili olduğu bulunmuştur (Granger ve ark., 1996).

Düşük molekül ağırlıklı enoksoparin tedavisi kiloya göre 
ayarlanmış heparin ile karşılaştırıldığında 30 günlük mortalite ve reinfarktüs riskinde ciddi azalma ile ilişkili olarak bulunmuştur. Fakat serebral olmayan kanama riskinde artışa neden olmaktadır (Giraldez ve ark., 2007). Bu yüzden doz yaş, ağırlık ve renal fonksiyona göre ayarlanmalıdır.

Fondaparinuks, fibrinolitik tedavi verilen hastalarda ölüm ve reinfarktüsü önlemede heparin ve plaseboya göre daha üstündür. Bivalirudinin streptokinaz ile beraber antikoagülan olarak kullanımını önerecek yeterli veri yoktur (Van de Werf ve ark., 2008).

\section{Perkütan koroner girişim (PKG)}

STEMI'nin erken saatlerindeki perkutan koroner girișimler (PKG); primer PKG, kolaylaştırılmış PKG ve kurtarıcı (rescue) PKG olarak üçe ayrılır.

\section{Primer perkütan koroner girişim}

Primer PKG, öncesinde veya beraberinde fibrinolitik tedavi uygulanmadan yapılan anjiyoplasti ve/veya stentleme olarak tanımlanır ve bir girişimsel kardiyolog ve deneyimli bir ekip tarafından hızlı bir şekilde uygulandığında tercih edilen tedavi metodudur. Primer PKG koroner açıklığın sağlanmasında ve devamında etkili olup fibrinolitiklere göre kanama riski daha düşük olan bir yöntemdir.

Fibrinolitik tedavi ile primer PKG'yi karşılaştıran randomize klinik çalışmalarda deneyimli ve yüksek hasta sayısına sahip merkezlerde primer PKG ile daha yüksek oranda koroner açıklık, daha az tekrar tıkanma, daha iyi sol ventrikül fonksiyonları ve en önemlisi daha iyi klinik sonuçlar elde edilmiştir. Rutin stent implantasyonu primer anjiyoplasti ile karşılaştırıldığında hedef damar revaskülarizasyon oranlarını azaltsa da ölüm ve reinfarktüs oranlarında ciddi azalma ile ilişkili bulunmamıştır (Mauri ve ark., 2008).

Primer PKG öncesi uzun süreli gecikmenin kötü klinik sonuçlara neden olduğu gösterilmiştir. PKG'ye bağlı gecikme, ilk tıbbi temas (ITT) ile balon şişirilmesi arasındaki süreden ITT ile fibrinolitik başlanması arasındaki teorik sürenin çıkarılması ile hesaplanır. Randomize çalışmalarda PKG'ye bağlı gecikme süresinin PKG lehine olabilmesi için 60-110 dakika arasında olması gerektiği gösterilmiştir (Betriu ve Masotti, 2005). Primer PKG (balon şişirilmesi) tüm vakalarda İTT sonrası 2 saat içerisinde yapılmalıdır özellikle risk altındaki canlı miyokard dokusu geniş olan hastalarda bu süre 90 dakika olmalıdır (Van de Werf ve ark., 2008).

Primer PKG fibrinolitik tedavi alması kontrendike olan hastalarda başarıyla uygulanabilir. Ayrıca, primer PKG kardiyojenik şoktaki hastalarda tercih edilen tedavi metodudur. Şoktaki hastalar dişında sadece sorumlu lezyonlar açılmalıdır. Sorumlu olmayan lezyonların tam revaskülarizasyonu daha sonraki bir dönemde tamamlanabilir (Van de Werf ve ark., 2008).

\section{Kolaylaştırılmış PKG}

Kolaylaştırılmış PKG, PKG'e bağlı gecikmeyi azaltmak amacıyla planlı PKG öncesinde farmakolojik reperfüzyon tedavisinin verilmesi olarak tanımlanır. Bu endikasyonda tam doz litik tedavi, glikoprotein IIb/IIIa (GPIIb/IIIa) inhibitörü ile beraber yarı doz litik tedavi ya da tek başına GPIIb/IIIa inhibitörü denenmiştir. PKG öncesi açıklık oranı yüksek olarak bulunmasına rağmen, bu yaklaşımın mortaliteye bir katkısı olmamıştır. İlave olarak daha fazla kanama komplikasyonu görülmüştür (Van de Werf ve ark., 2008).

\section{Kurtaricı (Rescue) PKG}

Kurtarıcı PKG, fibrinolitik tedaviye rağmen reperfüzyon sağlanamayan koroner artere uygulanan PKG olarak tanımlanır. Kurtarıcı PKG'nin başarısız fibrinolitik tedavi sonrası kullanımı uygun ve güvenilir bir metod olduğu çalışmalarda gösterilmiştir. Kurtarıcı PKG, konservatif metodlarla karş1laştırıldığında kalp yetersizliği ve reinfarktüs oranlarında anlamlı azalma, tüm nedenlere bağlı mortalitede azalma sağlamıştır. Fakat inme ve kanama komplikasyonu riskinde artışa neden olmaktadır (Wijeysundera ve ark., 2007).

\section{Ek antitrombotik tedavi}

\section{Aspirin, NSAID, COX2 inhibitorleri}

Aspirin STEMI tanısı düşünüldüğü anda mutlaka en kısa zamanda verilmelidir. Aspirine karşı bilinen hipersensitivite, aktif gastrointestinal kanama, bilinen pıhtılaşma bozukluğu ve şiddetli hepatik yetersizlik durumlarında verilmesi kontrendikedir. Nadiren astmatik hastalarda bronkospazmı tetikleyebilir. Aspirin çiğnenebilir formda 150-325 mg olarak başlanabilir daha sonra yaşam boyu 75-100 mg olarak devam edilir. Oral alım mümkün değilse 250-500 mg intravenöz form kullanılabilir. Fakat bu yaklaşımın klinik faydasını gösteren yeterli veri yoktur. Aspirin dışındaki non-steroid anti inflamatuar ilaçların ve selektif COX2 inhibitörlerinin STEMI hastalarında ölüm, reinfarktüs, kardiyak ruptür ve diğer komplikasyon riskini arttırdığı gösterilmiştir ve bu yüzden STEMI geçiren bir hastada mutlaka kesilmelidir (Gislason ve ark., 2006).

\section{Klopidogrel}

Klopidogrelin primer PKG uygulanan hastalarda daha az verisi olmasına rağmen aspirine üstün olduğuna dair yeterli kanıt vardır. Klopidogrel STEMI tanısıyla primer PKG girişim uygulanacak hastalara başlangıçta en az $300 \mathrm{mg}$, fakat daha güçlü ve hızlı antitrombotik etki amaçlanmışsa $600 \mathrm{mg}$ yükleme dozu ile başlanmalıdır. Daha sonra 12 ay süre ile günde $75 \mathrm{mg}$ olarak devam edilebilir (Van de Werf ve ark., 2008).

\section{Glikoprotein IIb/IIIa inhibitörleri}

STEMI'e hastalarında yapılan çalışmalarda glikoprotein IIb/IIIa (GIIb/IIIa) inhibitörlerinden abciximab diğer GIIb/ IIIa inhibtörleri olan tirofiban ve eptifibatide göre daha fazla kullanılmıştır. Abciximab hemorajik inme ve majör kanama riskini etkilemeksizin 30 günlük mortalitede \%32 azalma sağlamıştır (De Luca ve ark., 2005). Planlanmış PKG öncesinde bu ilacın başlanmasının kateter laboratuarında başlanması ile karşılaştırıldığı çalışmalarda damar açıklığı arasında gruplar arasında farklılık saptanmamıştr.

\section{Heparin}

STEMI'da heparin PKG sırasında standart antikoagülan tedavidir. Heparin başalangıçta IV 100 U/kg bolus (GIIb/IIIa inhibitörleri ile beraber kullanılıyorsa $60 \mathrm{U} / \mathrm{kg}$ ) olarak verilir. Girişimsel işlemlerin ACT (aktive kloting zamanı) takibi altında yapılması önerilmektedir ve işlem boyunca ACT 250-350 sn (GIIb/IIIa inhibitörleri kullanılıyorsa 200-250 sn) olacak şekilde tutulmalıdır (Van de Werf ve ark., 2008). 


\section{Bivaluridin}

Bivaluridin direkt trombin inhibitörüdür ve HORIZONSAMI çalışmasında PKG hastalarında test edilmiştir. Majör advers kardiyak olayları majör kanamada \%40 azalma ile beraber anlamlı derecede düşürmüştür (Stone ve ark., 2008). Bivaluridin PKG sirasında IV bolus verildikten sonra infüzyon olarak verilir. Takibinde ACT bakılmasına gerek yoktur.

\section{Koroner arter bypass greft (KABG) ameliyatı}

Akut dönemde KABG gereken hasta sayısı sınırlı olmakla beraber, başarısız PKG sonrası, PKG sonrası refraktör semptomlar, kardiyojenik şok, ventriküler ruptür, akut mitral yetersizlik ve ventriküler septal defekt gibi mekanik komplikasyonlar nedeniyle uygulanabilir (Van de Werf ve ark., 2008).

Reperfüzyon tedavisi uygulanmayan hastalarda antitrombotik tedavi

Herhangi bir nedenle reperfüzyon tedavisi uygulanmamış ve semptom başlangıcından 12 saat sonra başvuran hastalarda aspirin, klopidogrel ve bir antikoagülan (heparin, enoksaparin ya da fondaparinuks) mutlaka verilmelidir. Bu özel grupta yapılan çalışmalarda fondaparinuks heparine üstün olarak bulunmuştur (Oldgren ve ark., 2008). Kontrendikasyon yoksa taburcu etmeden önce koroner anjiyografi yapılmalıdır (Van de Werf ve ark., 2008).

\section{Akut dönemdeki diğer tedaviler}

Beta blokörler

Beta blokörlerin (BB) STEMI sonrası uzun dönemde etkinliğinin birçok çalışmada kanıtı olmasına rağmen erken dönemde IV olarak kullanımının bir katkısı bulunmamıştır. Hipotansiyon ve konjestif kalp yetersizliği semptomları olan hastalarda IV BB kullanımı kontrendikedir. Erken dönemde BB tedavinin başlanması için hastanın hemodinamik olarak stabil hale gelmesi beklenmelidir (Van de Werf ve ark., 2008).

\section{Nitratlar ve kalsiyum kanal blokörleri}

Erken dönemde rutin olarak kullanılmalarının bir faydası çalışmalarda gösterilmemiştir.

\section{Anjiyotensin dönüştürücü enzim (ADE) inhibitörleri ve anjiyotensin reseptör blokörleri (ARB) \\ ADE inhibitörleri erken dönemde düşük ejeksiyon frak- siyonu $(\mathrm{EF} \leq \% 40)$ kalp yetersizliği semptomları olan hasta- lara bir kontrendikasyon yoksa ilk 24 saat içerisinde mutlaka verilmelidir. ADE inhibitörlerini tolere edemeyen hastalara ARB başlanmalıdır (Van de Werf ve ark., 2008).}

\section{KAYNAKLAR}

Betriu, A., Masotti, M., 2005. Comparison of mortality rates in acute myocardial infarction treated by percutaneous coronary intervention versus fibrinolysis. Am. J. Cardiol. 95, 100-101.

Chen, Z.M., Jiang, L.X., Chen, Y.P., Xie, J.X., Pan, H.C., Peto, R., Collins, R., Liu, L.S., 2005. Addition of clopidogrel to aspirin in 45, 852 patients with acute myocardial infarction: Randomised placebo-controlled trial. Lancet. 366, 1607-1621.

De Luca, G., Suryapranata, H., Stone, G.W., Antoniucci, D., Tcheng, J.E., Neumann, F.J., Van de Werf, F., Antman, E.M., Topol, E.J., 2005. Abciximab as adjunctive therapy to reperfusion in acute ST-segment elevation myocardial infarction: A meta-analysis of randomized trials. JAMA. 293, 1759-1765.

Giraldez, R.R., Nicolau, J.C., Corbalan, R., Gurfinkel, E.P., Juarez, U., Lopez-Sendon, J., Parkhomenko, A., Molhoek, P., Mohanavelu, S., Morrow, D.A., Antman, E.M., 2007. Enoxaparin is superior to unfractionated heparin in patients with ST elevation myocardial infarction undergoing fibrinolysis regardless of the choice of lytic: An ExTRACT-TIMI 25 analysis. Eur. Heart J. 28, 1566-1573.

Gislason, G.H., Jacobsen, S., Rasmussen, J.N., Rasmussen, S., Buch, P., Friberg, J., Schramm, T.K., Abildstrom, S.Z., Køber, L., Madsen, M., Torp-Pedersen, C., 2006. Risk of death or reinfarction associated with the use of selective cyclooxygenase-2 inhibitors and nonselective nonsteroidal antiinflammatory drugs after acute myocardial infarction. Circulation. 113, 2906-2913.

Gore, J.M., Granger, C.B., Simoons, M.L., Sloan, M.A., Weaver, W.D., White, H.D., Barbash, G.I., Van de Werf, F., Aylward, P.E., Topol, E.J., 1995. Stroke after thrombolysis. Mortality and functional outcomes in the GUSTO-I trial. Global use of strategies to open occluded coronary arteries. Circulation. 92, 2811-2818.

Granger, C.B., Hirsch, J., Califf, R.M., Col, J., White, H.D., Betriu, A., Woodlief, L.H., Lee, K.L., Bovill, E.G., Simes, R.J., Topol, E.J., 1996. Activated partial thromboplastin time and outcome after thrombolytic therapy for acute myocardial infarction: Results from the GUSTO-I trial. Circulation. 93, 870-878.

Hamm, C.W., Möllmann, H., Bassand, J., Van de Werf, F., 2009. Acute coronary syndromes. Esc textbook of cardiovascular medicine. 2. Bask1 A.J. Camm, T.F. Lüscher, Serruys P.W. eds. Oxford University Press, pp. 535-596.

ISIS-2 (Second International Study of Infarct Survival) Collaborative Group, 1988. Randomised trial of intravenous streptokinase, oral aspirin, both, or neither among 17,187 cases of suspected acute myocardial infarction: ISIS-2. Lancet pp. 349-360.

Le May, M.R., Wells, G.A., Labinaz, M., Davies, R.F., Turek, M., Leddy, D., Maloney, J., McKibbin, T., Quinn, B., Beanlands, R.S., Glover, C., Marquis, J.F., O'Brien, E.R., Williams, W.L., Higginson, L.A., 2005. Combined angioplasty and pharmacological intervention versus thrombolysis alone in acute myocardial infarction (CAPITAL AMI study). J. Am. Coll. Cardiol. 46, 417-424.

Mauri, F., Gasparini, M., Barbonaglia, L., Santoro, E., Grazia Franzosi, M., Tognoni, G., Rovelli, F., 1989. Prognostic significance of the extent of myocardial injury in acutemyocardial infarction treated by streptokinase (the GISSI trial). Am J Cardiol. 63, 1291-5.

Mauri, L., Silbaugh, T.S., Garg, P., Wolf, R.E., Zelevinsky, K., Lovett, A., Varma, M.R., Zhou, Z., Normand, S.L., 2008. Drug-eluting or baremetal stents for acute myocardial infarction. N. Engl. J. Med. 359, 1330-1342.

Oldgren J., Wallentin, L., Afzal, R., Bassand, J.P., Budaj, A., Chrolavicius, S., Fox, K.A., Granger, C.B., Mehta, S.R., Pais, P., Peters, R.J., Xavier, D., Zhu, J., Yusuf, S., 2008. Effects of fondaparinux in patients with ST-segment elevation acute myocardial infarction not receiving reperfusion treatment. Eur. Heart J. 29, 315-323.

Sabatine, M.S., Cannon, C.P., Gibson, C.M., López-Sendón, J.L., Montalescot, G., Theroux, P., Claeys, M.J., Cools, F., Hill, K.A., Skene, A.M., McCabe, C.H., Braunwald, E., 2005. Addition of clopidogrel to aspirin and fibrinolytic therapy for myocardial infarction with ST-segment elevation. N. Engl. J. Med. 352, 1179-1189. 
Steg, P.G., Bonnefoy, E., Chabaud, S., Lapostolle, F., Dubien P.Y., Cristofini, P., Leizorovicz, A., Touboul, P., 2003. Impact of time to treatment on mortality after prehospital fibrinolysis or primary angioplasty: Data from the CAPTIM randomized clinical trial. Circulation. 108, 28512856.

Stone, G.W., Witzenbichler, B., Guagliumi, G., Peruga, J.Z., Brodie, B.R., Dudek, D., Kornowski, R., Hartmann, F., Gersh, B.J., Pocock, S.J., Dangas, G., Wong, S.C., Kirtane, A.J., Parise, H., Mehran, R., 2008. Bivalirudin during primary PCI in acute myocardial infarction. N. Engl. J. Med. 358, 2218-2230.

Topol, E., Califf, R., Van de Werf, F., Armstrong, PW., Aylward, P., Barbash, G., Bates, E., Betriu, A., Boissel, JP., Chesebro, J., Col J, de Bono D, Gore, J., Guerci, A., Hampton, J., Hirsh, J., Holmes, D., Horgan, J., Kleiman, N., Marder, V., Morris, D., Ohman, M., Pfisterer, M., Ross, A., Rutsch, W., Sadowski, Z., Simoons, M., Vahanian, A., Weaver, WD., White, H., Wilcox, R. The GUSTO investigators, 1993. An international randomized trial comparing four thrombolytic strategies for acute myocardial infarction. N. Engl. J .Med. 329, 673-682.

Topol, E., Califf, R., Van de Werf, F., Armstrong, PW., Aylward, P., Barbash, G., Bates, E., Betriu, A., Boissel, JP., Chesebro, J., Col, J., de Bono, D., Gore, J., Guerci, A., Hampton, J., Hirsh, J., Holmes, D., Horgan, J., Kleiman, N., Marder, V., Morris, D., Ohman, M., Pfisterer, M., Ross, A., Rutsch, W., Sadowski, Z., Simoons, M., Vahanian, A., Weaver, WD., White, H., Wilcox, R. The GUSTO investigators, 1997. A comparison of reteplase with alteplase for acute myocardial infarction. N. Engl J. Med. 337, 1118-1123.

Van De Werf, F., Adgey, J., Ardissino, D., Armstrong, P.W., Aylward, P., Barbash, G., Betriu, A., Binbrek, A.S., Califf, R., Diaz, R., Fanebust, R., Fox, K., Granger, C., Heikkilä, J., Husted, S., Jansky, P., Langer, A., Lupi, E., Maseri, A., Meyer, J., Mlczoch, J., Mocceti, D., Myburgh, D., Oto, A., Paolasso, E., Pehrsson, K., Seabra-Gomes, R., Soares-Piegas, L., Sùgrue, D., Tendera, M., Topol, E., Toutouzas, P., Vahanian, A., Verheugt, F., Wallentin, L., White, H., 1999. Single-bolus tenecteplase compared with front-loaded alteplase in acute myocardial infarction: The ASSENT-2 double-blind randomised trial. Lancet. 354, 716-722.

Van de Werf, F., Bax, J., Betriu, A., Blomstrom-Lundqvist, C., Crea, F., Falk, V., Filippatos, G., Fox, K., Huber, K., Kastrati, A., Rosengren, A., Steg, P.G., Tubaro, M., Verheugt, F., Weidinger, F., Weis, M., 2008. Management of acute myocardial infarction in patients presenting with persistent ST-segment elevation: The task force on the management of ST-Segment elevation acute myocardial infarction of the European society of cardiology. Eur. Heart J. Dec. 29, 2909-2945.

Wijeysundera, H.C., Vijayaraghavan, R., Nallamothu, B.K., Foody, J.M., Krumholz, H.M., Phillips, C.O., Kashani, A., You, J.J., Tu, J.V., Ko, D.T., 2007. Rescue angioplasty or repeat fibrinolysis after failed fibrinolytic therapy for ST-segment myocardial infarction: A meta-analysis of randomized trials. J. Am. Coll. Cardiol. 49, 422-430. 